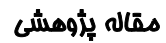

\section{كيفيت زندكى مرتبط با سلامت دانشجويان دانشكاه علوم بزشكى خراسان شمالى}

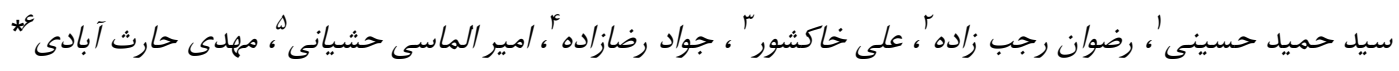

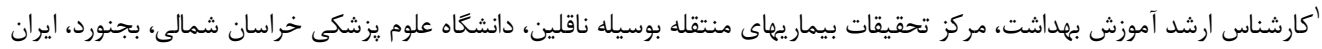

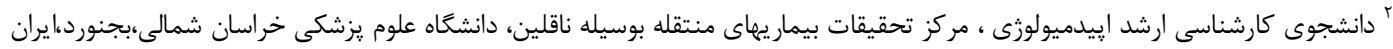

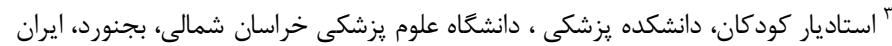

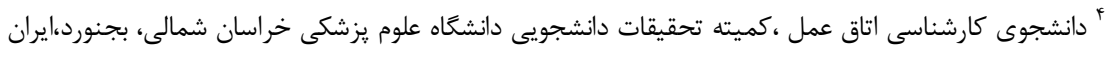

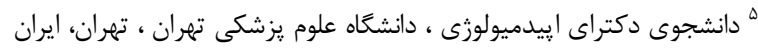

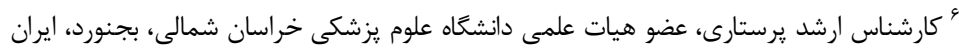

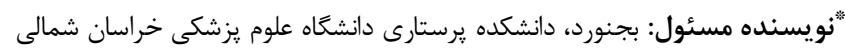

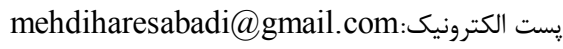

جكيده

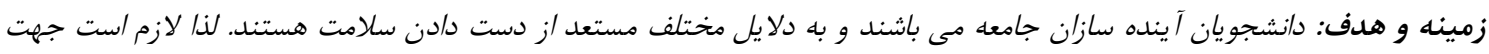

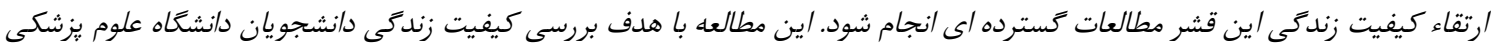

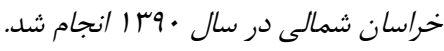

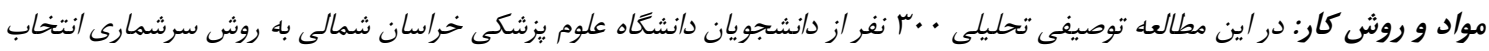

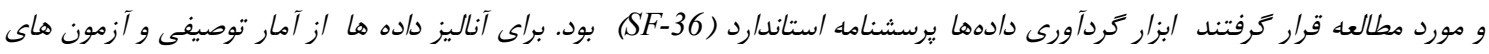

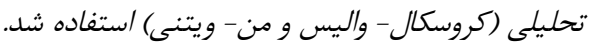

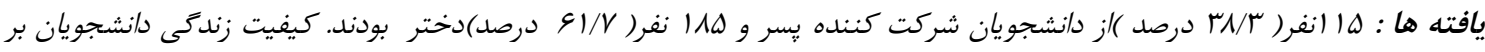

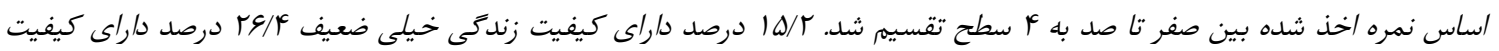

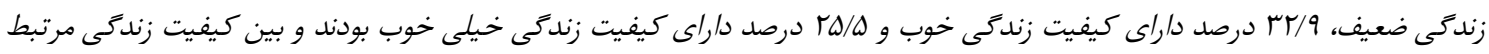

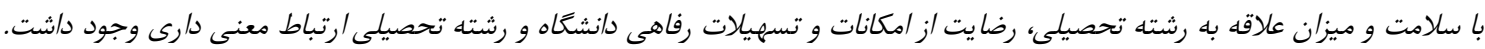

. $(P \leq \cdot / \cdot 1)$

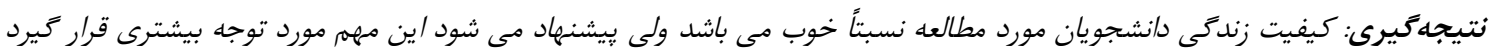

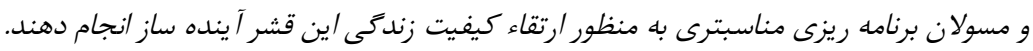

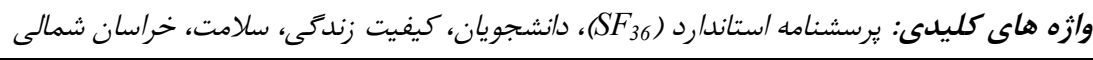

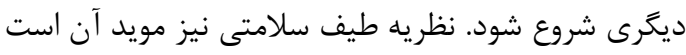
مقدمه

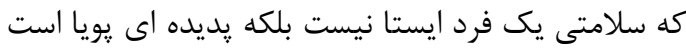

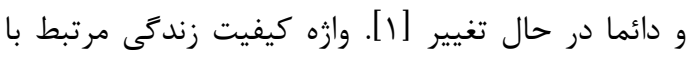

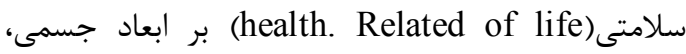

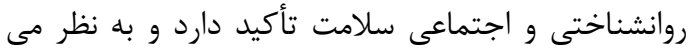

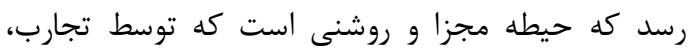
عقايد، انتظارات و احساسات فردتحت تأثير قرار مئ كي كيرد

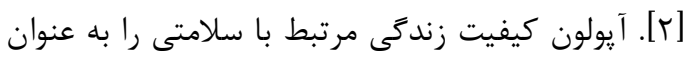

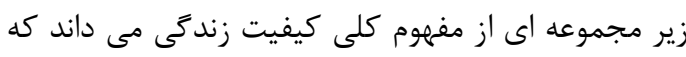

سلامتى به مفهوم گسترده لغوى آن تنها به معنى نبودن يا

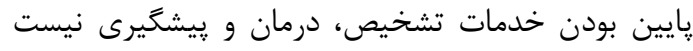

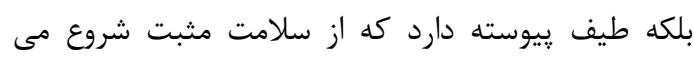

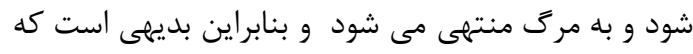

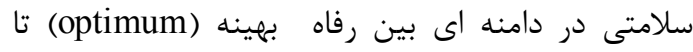

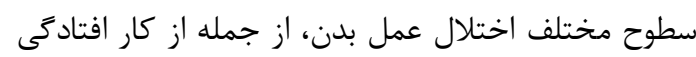

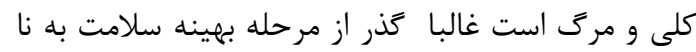

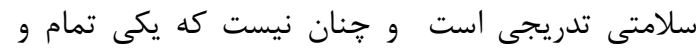


هستند و لازم است سلامت آنها سنجيده شود تا بتوان براى برنامه ريزى به منظور بهبود كيفيت زندكى و ارتقاء

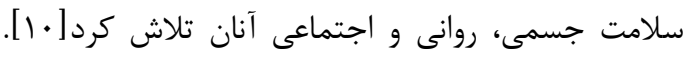

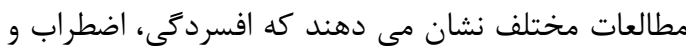

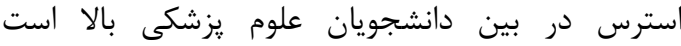

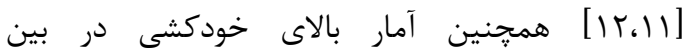
دانشجويان يزشكى نشان دهنده اهميت توجه به كيفيت

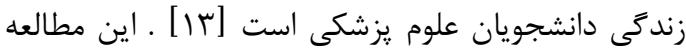

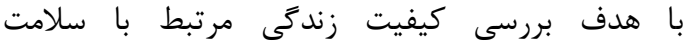
دانشجويان دانشخاه علوم يزشكى خراسان شمالى و و عوامل

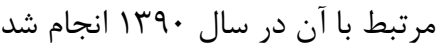

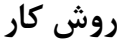
اين تحقيق از نوع توصيفى تحليلى بود. واحدهاى يزوهش

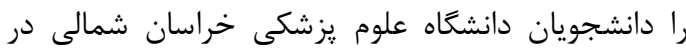

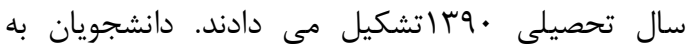

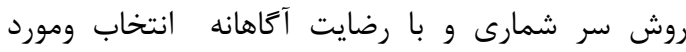
بررسى قرار كرفتند كه در نهايت اسب دانشجو يرسشنامه

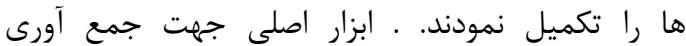

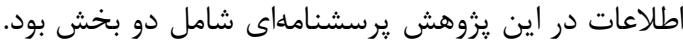

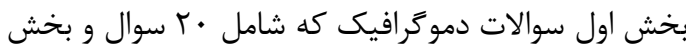
دوم سوالات سنجش كيفيت زندگى مرتبط با سلامت

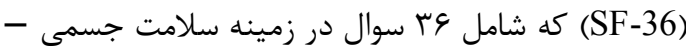
محدوديت نقش جسمى و روانى - درد بدنى - سلامت عمومى - سرزندگى - كاركرد اجتماعى و سلامت ذهنى

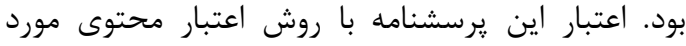

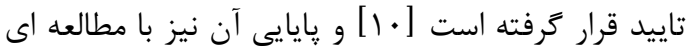

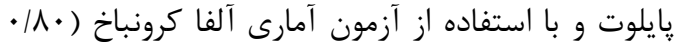

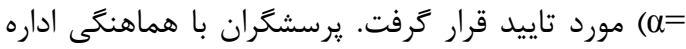

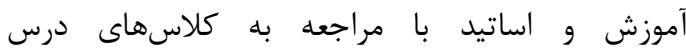

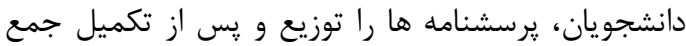

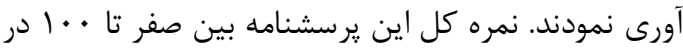

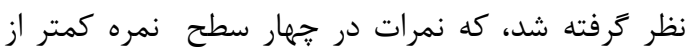

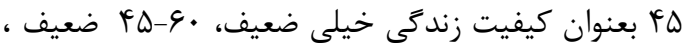

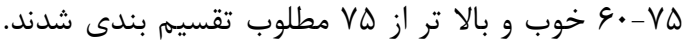

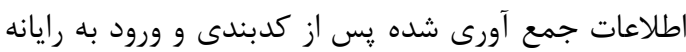
از طريق نرم افزار آمارى SPSS16 وآزمون هاى آمارى لدى
به سلامت فرد در سه بعد جسمى، روانى و اجتماعى بستگى دارد. به نظر ويلسون و كلرى رضايت و خشنودى

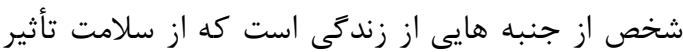

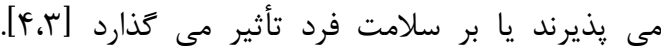
كيفيت زندگى بر اساس تعريف كروه كيفيت زندكى

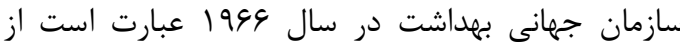

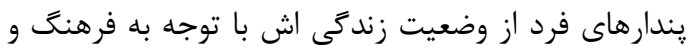

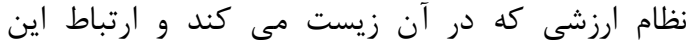

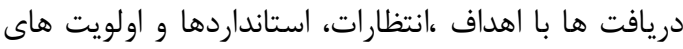

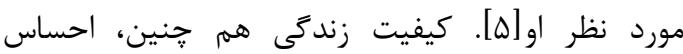

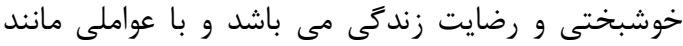
سن، فرهنگ، جنس، تحصيلات، وضع طبقاتى، بيمارى و و

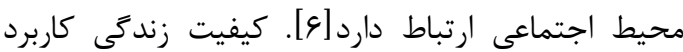
زيادى در علوم يزشكى دارد و تحت عنوان كيفيت زندگى آنى

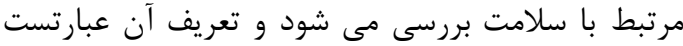

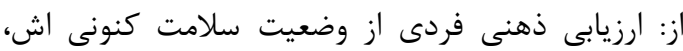
مراقبت هاى بهداشتى، فعاليتهاى ارتقاءدهنده سلامتى كه آرد

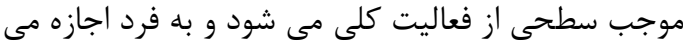

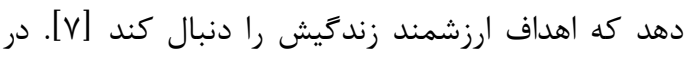
حال حاضر كيفيت زندگى يكى از نترانيهاى عمده متخصصان بهداشت است و به عنوان شاخصى براى اندازه كيرى و ضعيت سلامت در تحقيقات بهداشتى شناخته شده است كيفيت زندگى، ميزان رفاه جسمى ،روان

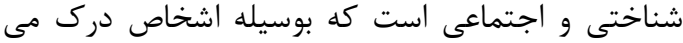
شود و نشان دهنده ميزان رضايت فرد از مو هبت هاى إنى زندكى است. هدف از مطالعه كيفيت زندكى و نتايج منتج

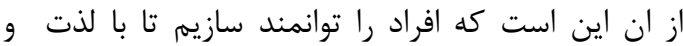

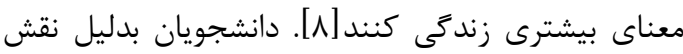
مهمى كه در اداره آينده كشور به عهيده دارند، يكى از قشرهاى مهم جامعه به حساب مى آيند. دانشجويان نه

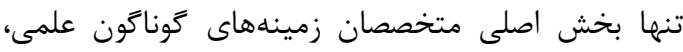
فنى و هنرى هر كشورى را تشكيل خواهند داد، بلكه اين كروه مديران اصلى در آينده كشور و رهبر اقشار جامعه در

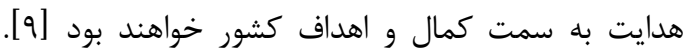
دانشجويان بنا به دلايل مختلفى از جمله، شرايط خاص دوره جوانى، حجم زياد درسها، مشكلات اقتصادى، آينده شغلى مبهم و نامشخص مستعد از دست دادن سلامت زئاد درسات 
جدول 1 وضعيت كيفيت زندگى مرتبط با سلامت را در

بين دانشجويان نشان مى دهد. بين كيفيت زندكى مرتبط

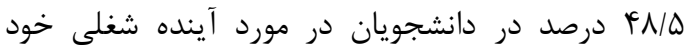

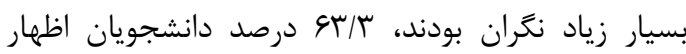
كردند كه رضايت آنان از امكانات رفاهى دانشعاه كم است. با سلامت دانشجويان و ميزان علاقه به رشته تحصيلى

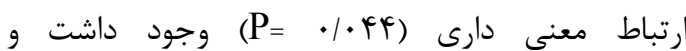
دانشجويانى كه به رشته تحصيلى خود كم علاقه بودند كيفيت زندگى يايين ترى را نسبت به دانشجويانى كه به

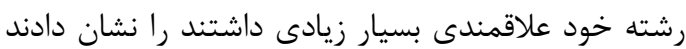
(جدول ז). بين نمر ه كيفيت زندگى مرتبط با سلامت بادي دانشجويان و ميزان رضايت از امكانات خوابخاهى و وناه

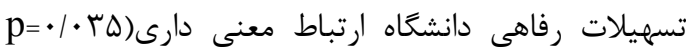
وجود داشت به طورى كه با كاهش ميزان رضايت از

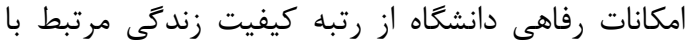

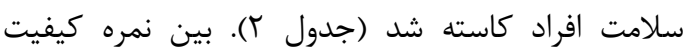
زندگى مرتبط با سلامت دانشجويان و رشته تحصيلى

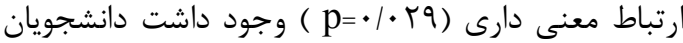
يزشكى كمترين كيفيت زندگى و دانشجويان فوريت
من- ويتنى و كروسكال - واليس مورد تجزيه تحليل قرار كرفت. - مين

يافته ها

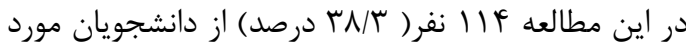

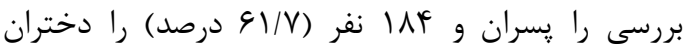

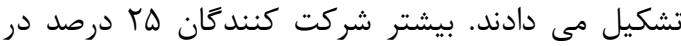
رشته يرستارى مشغول به تحصيل بودند و كمترين تعداد

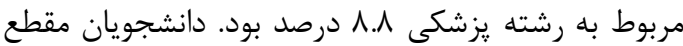

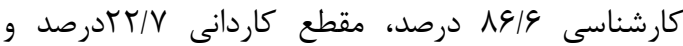
دكتراى حرفه اى N/V درصدشركت كنند مى دادند. ميزان در آهد خانواده بيشتر شركت كنيندكان

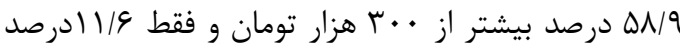

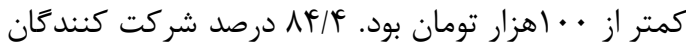

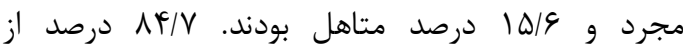

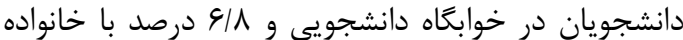

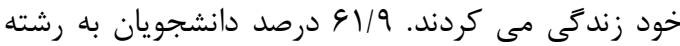
تحصيلى خود علاقه مندى بسيار بالايى داشتند و V درصد به رشته تحصيلى خود علاقه مندى خيلى كم داشتند.

جدول ا: توزيع فراوانى كيفيت زندكى افراد مورد بررسى

\begin{tabular}{|c|c|}
\hline تعداد (درصد) & كيفيت زندكى \\
\hline$r \Delta(1 \Delta / r)$ & خيلى ضعيف (كمتر از \&ه) \\
\hline$G \mid(Y G / F)$ & ضعيف(FD-F) \\
\hline$V G(T r / q)$ & خوب(· • \\
\hline$\Delta q(T \Delta / \Delta)$ & مطلوب (بالا تر از VD) \\
\hline (1) (1) & جمع \\
\hline
\end{tabular}


جدول r: رابطه بين ميانكَين رتبه كيفيت زندكى مرتبط با سلامت دانشجويان با ميزان علاقه به رشته تحصيلى ، ميزان رضايت از

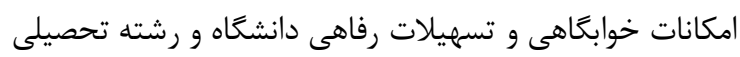

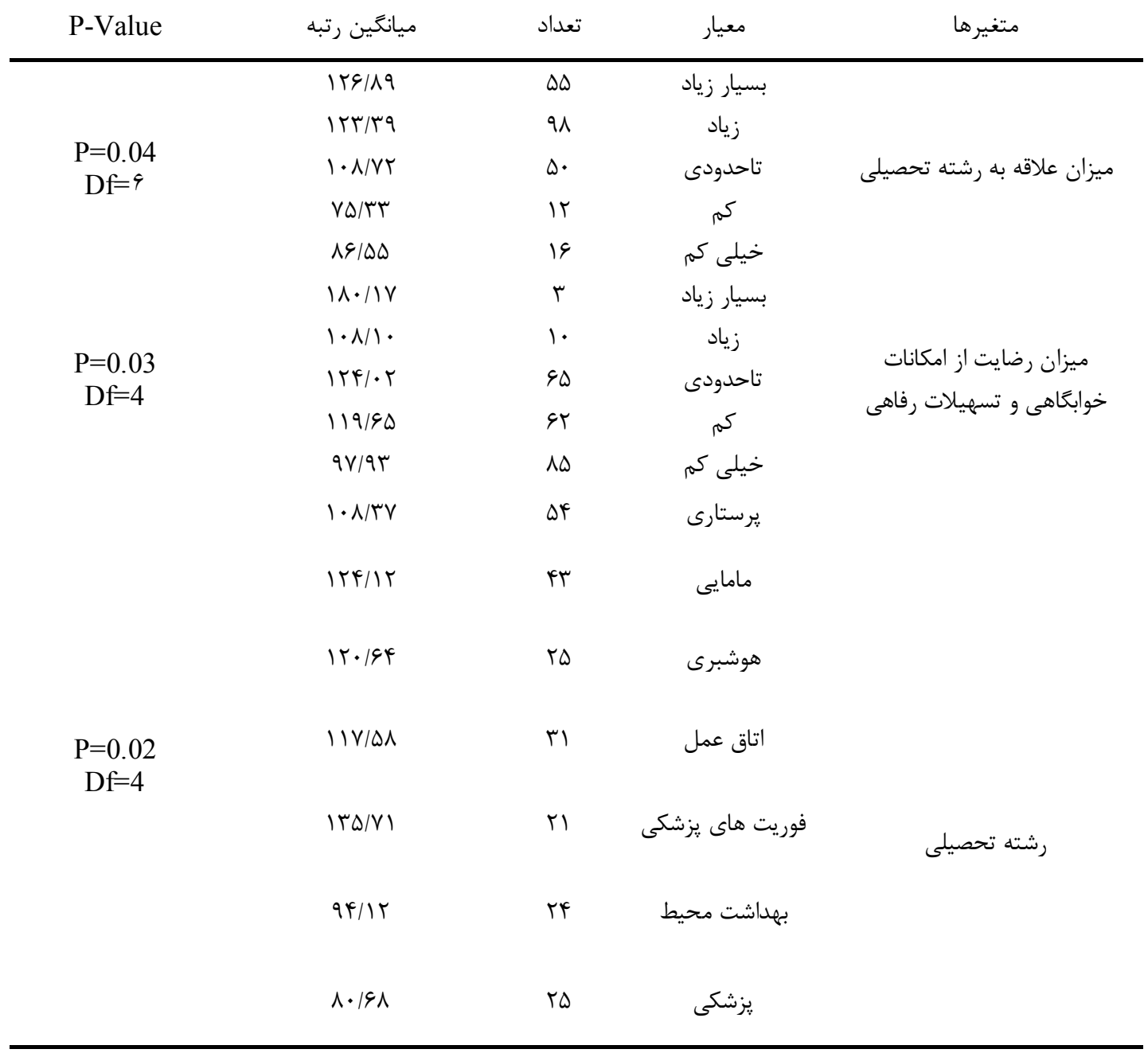

هيج يك از افرادى كه رشته تحصيلى آنها فوريت يزشكى

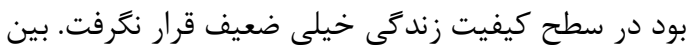
ميانگين رتبه كيفيت زندگى مرتبط با سلامت دانشجويان

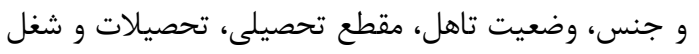

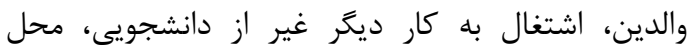

يزشكى بيشترين كيفيت زندكى را داشتند (جدول ؟)

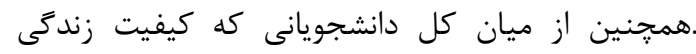
مرتبط با سلامت مطلوب داشتند فقط يك درصد آنها در در درئر

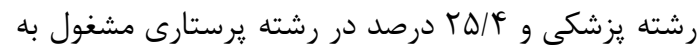

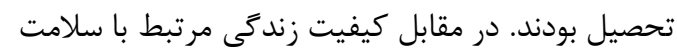


مطالعه امينى كيفيت زندَّى يسران بيشتر از دختران بود

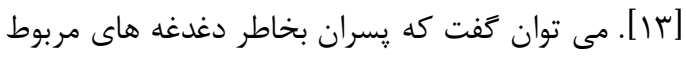

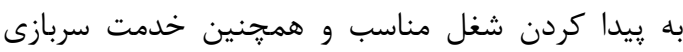

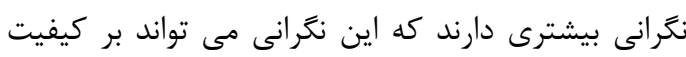

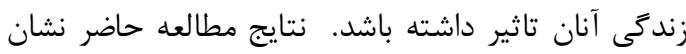

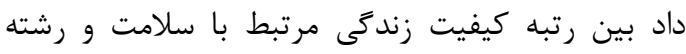

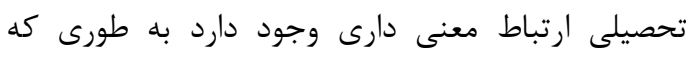

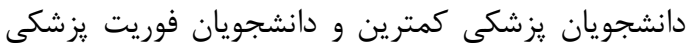
بيشترين رتبه كيفيت زندكى را داشتند. در مطالعه اي كه واند

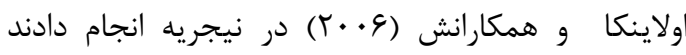

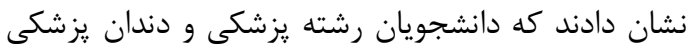

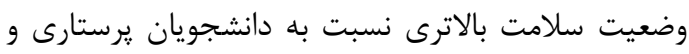

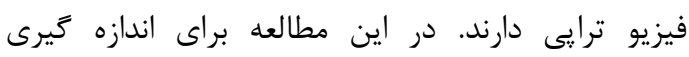

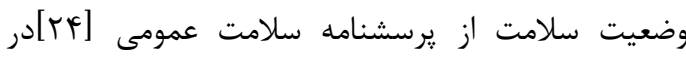

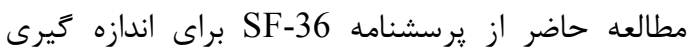
كيفيت زندگى استفاده شد. مطالعه امينى و و همكاران

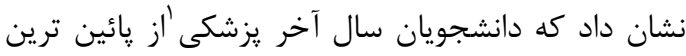

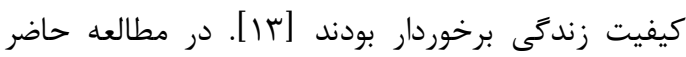

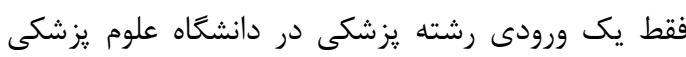

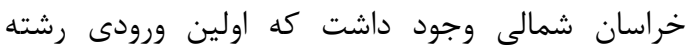

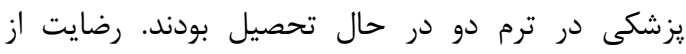

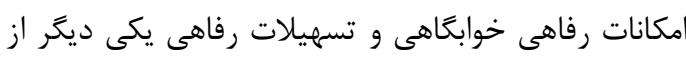

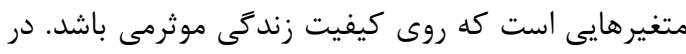

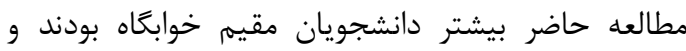

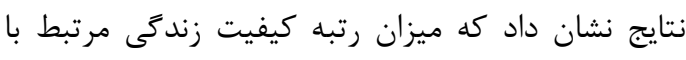
سلامت در كسانى كه رضايت بيشترى از امكانات

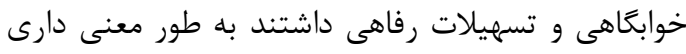

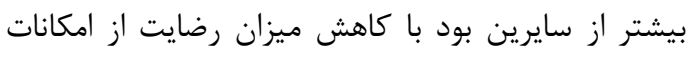

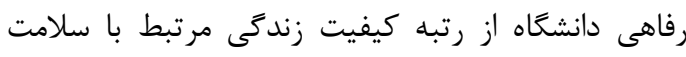

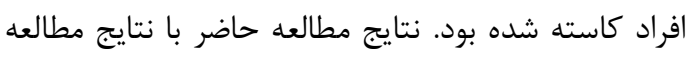
منصوريان و همكاران همخوانى داشت [ـ [1]. نتيجه كيرى توجه به كيفيت زندكى دانشجويان دانشخاه هاى علوم

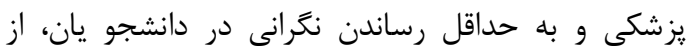

سكونت و نكَرانى در مورد آينده شغلى رابطه معنى دار آمارى مشاهده نشد. توجه به كيفيت زندكى دانشجويان رشته هاى علوم

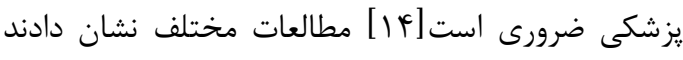

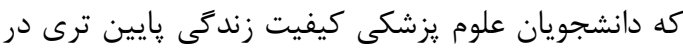

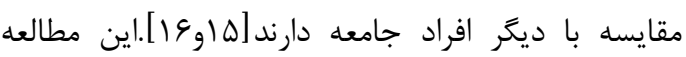

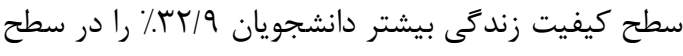

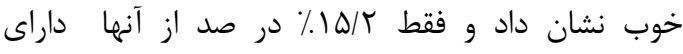
كيفيت زندىى خيلى ضعيف بودند. مطالعه حاضر نشان

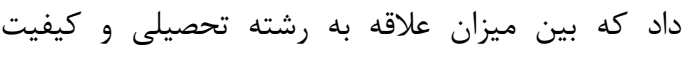

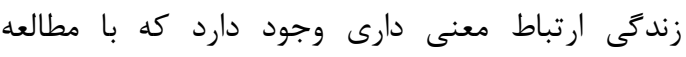

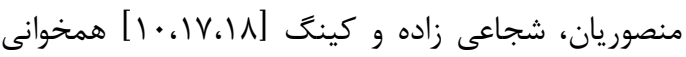

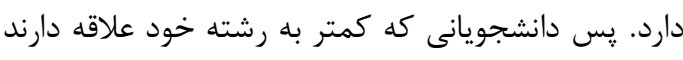

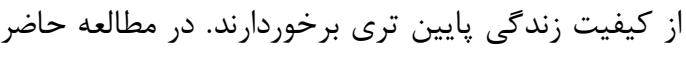

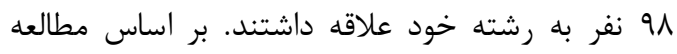

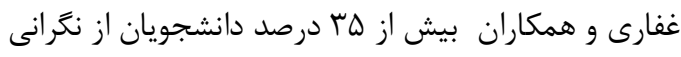

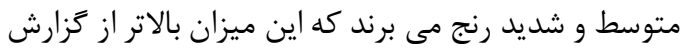

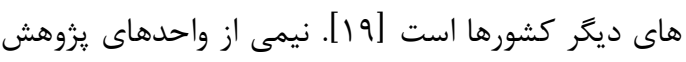

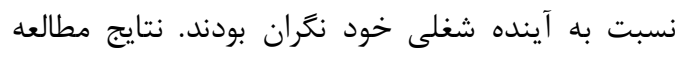

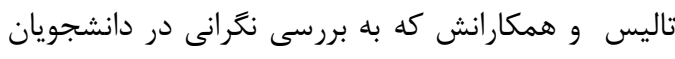

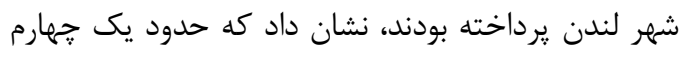

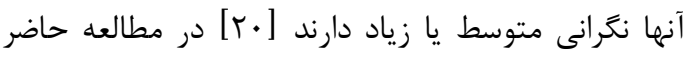

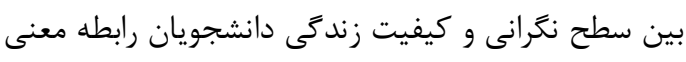

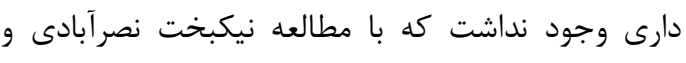

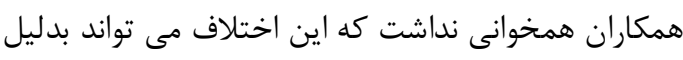

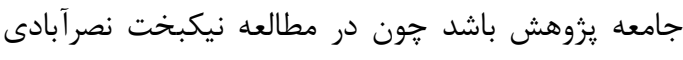

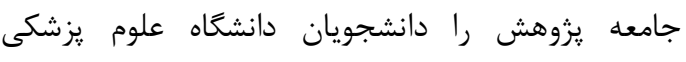

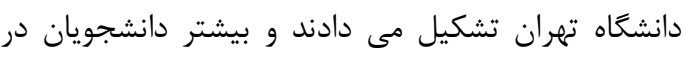

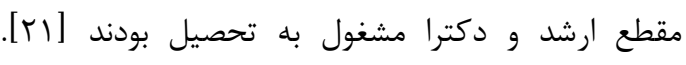

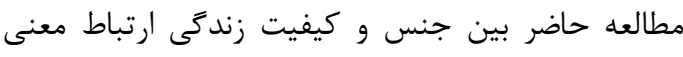

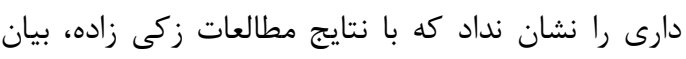

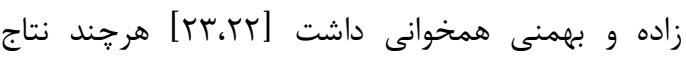

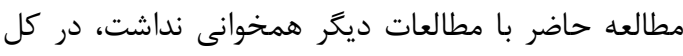

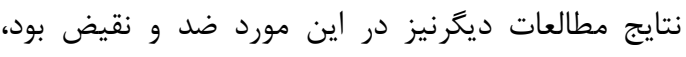

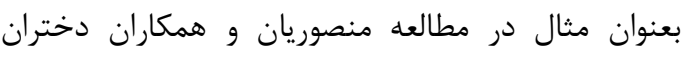

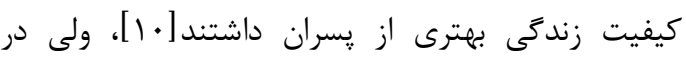


وظيفه خود مى دانند از همكارى و مساعدت معاونت

محترم يزوهشى دانشگاه علوم يزشكى خراسان شمالى و ونى

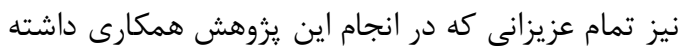

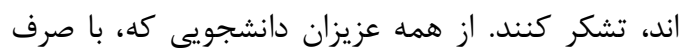

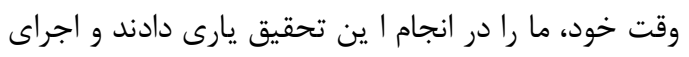

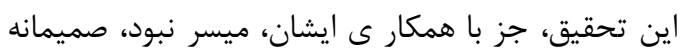

$$
\text { تشكرمى نماييم. }
$$

\section{References}

1. shojaee,Tehrani,H. Medical Textbook prevention, volume2 .J.A.PARK,translated gilan university of medical science, 2004.

2. Testa MA, Simonson DC . Assessment of qol outcomes. J Med 1997; 343(13): 835-840.

3. Anderson K I, Burckhardt CS. Conceptualization and measurement of qol as an outcome variable for health care intervention and research. J Adu Nurs 1999; 29(2): 298-306.

4. Peplau HE. QOL an interpersonal perspective. Scien Quarterly Nurse 1999 ; 7(1): $10-15$

5. leininger,M.Quality of life from a tran cultural nursing perspective.nursing science Quarterly2002: 7(1):22-28.

6. King CR,Hinds PS.Quality of life :from nursing and patien perspectives:teory, research practice boston: jones \&Bartlett publishers,2003

7. L. M ,quality of life from a trans cultural nursing perspective, nur ,sci -2006-Donald A.what is quality of life ? clinical lecture in epidemiology university college London, BMBCH 1998: 80

8 . King CR . over viev of quality of life and controversial issues . in:king CR, Hinds ps. Quality of life from nursing and patient perspective . Canada : jones and Bartlett :1998:p:22-30

9. Rezaei Adaryani M, Azadi A, Ahmadi F, Vahedian A. Comparison of depression, anxiety, stress and quality of life in dormitories students of Tarbiat Modares University. Iranian Journal of Nursing Research 2007; 2(45): 31-38.

10.Mansourian M., Behnampour N., Kargar M., Rahimzadeh H. Health-related quality of life (HRQOL) among Gorgan University of medical sciences students. Journal of Gorgan

$$
\begin{aligned}
& \text { قبيل رفع مشكلات مالى، دغدغه هاى شغلى، ارتقاى سطح } \\
& \text { امكانات رفاهى و خوابگاهى و ارتقاى سطح امنيت روانى، از }
\end{aligned}
$$

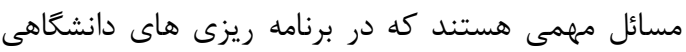

$$
\begin{aligned}
& \text { مى توانند مدنظر مسئولان امر قرار كيرند. } \\
& \text { تشكر و قدردانى } \\
& \text { اين مقاله حاصل انجام طرحى تحقيقاتى مصوب معاونت } \\
& \text { يثزوهشى دانشگاه علوم يزشكى خراسان شمالى است كه با }
\end{aligned}
$$

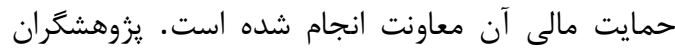

Bouyeh Faculty of Nursing \& Midwifery 2006;(10): 16-20 (persian).

11. Guthrie EA, Black D, Shaw CM, Hamilton J,Creed FH, Tomenson B. Embarking upon a medical career: psychological morbidity infirst year medical students. Med Educ. 1995; 29: 337-41.

12. Carson AJ, Dias S, Johnston A, et al. Mental health in medical students: a case control study using the 60 item General Health Questionnaire. Scott Med J. 2000; 45:115-116. 13.Amini M, Safaee Ardekani Gh, Golkar A, et al. Quality of Life of Medical Students in Different Stages - A Multi Center Study. Journal of Medical Education Winter and Spring 2007; 11 (1,2): 13-19.

14.Ad Hoc Committee of Deans. Educating Doctors to Provide High Quality Medical Care: A Vision for Medical Education in the United States. Washington, DC: Association of American Medical Colleges; 2004

15.Dyrbye LN, Thomas MR, Shanafelt TD. Systematic review of depression,Anxiety and other indicators of psychologic distress among U.S. and Canadian medical students. Acad Med. 2006;81(4):354-373.

16.Dahlin M, Joneborg N, Runeson B. Stress and depression among medical students: a cross-sectional study. Med Educ. 2005;39(6):594-604.

17.Shojaei-Zadeh D, Mansourian M, Aghaz M. Health-related quality of life of students under Imam Khomeini commite in Tehran in 2005. Emdad Pajohan Journal. Third Year, No. 10, Summer 2005 p. (persian).

18.King C, Hands P. QOL from nursing and patien perspective theory. Research Practice Jones \& Bartlett2003PP168-174.

19.Ghafari F. Worry domains among the Students of Mashad Medical Sciences Universities. MSc thesis in Nursing, School of 
Nursing and Midwifery, Mashhad University of Medical Sciences, 2001 (persian).

20.Tallis F, Davey G, Copuzzo N. The phenomenology of non pathologic worry. Behavioral and Cognative Psychology 1992; 22: 37-56.

21.Alireza Nikbakht Nasrabadi, Seyyed Reza Mazloom, Maryam Nesari, Fatemeh Goodarzi. Relation between worry domains and health related quality of life in medical sciences students. Payesh, Journal of The Iranian Institute For Health Sciences Research 2009;8(1): 85-92.(persian).

22.Zaki M. A. Quality of Life and its Relationship with Self-esteem in Male and Female Students of Isfahan University. Iranian
Journal of Psychiatry and Clinical Psychology (Andeesheh Va Raftar) 2008;13(4): 416-419 (persian). .

23.Bahmani B,Tamadon M, Asgari M. Quality of life and its relationship with religious attitudes and academic performance of students of Islamic Azad University South Tehran. Medicine and the cultivation of summer 1383; (53) :32-44.

24. Olayinka O. Omigbodun $Æ$ Akin-Tunde $A$ and et al. Stressors and psychological symptoms in students of medicine and allied health professions in Nigeria. Soc Psychiatry Psychiatr Epidemiol (2006) 41:415-421. 
Original Article

\title{
Health-related quality of life in students of North khorasan University of medical Sciences in 2011
}

\author{
Hosseini $\mathrm{SH}^{1}$. Rajabzadeh $\mathrm{R}^{2}$.khakshour $\mathrm{A}^{3}$, Rezazadeh $\mathrm{J}^{4}$,Almasi Hashiani $\mathrm{A}^{5}$. Haresabadi $\mathrm{M}^{6^{*}}$
}

1. M.Sc of Health Science, Vector-bor ne Diseases Research Center, North Khorasan University of Medical Sciences, Bojnurd, Iran.

2. B.Sc of Health Science Vector-borne Diseases Research Center, North Khorasan University of Medical Sciences, Bojnurd, Iran.

3 Associate Professor of Pediatrics,. North Khorasan University of Medical Sciences, Bojnurd, Iran

4. North Khorasan University of Medical Sciences, Bojnurd, Iran

5. Department of Epidemiology, Tehran University of Medical Sciences, Tehran, Iran

6. North Khorasan University of Medical Sciences, Bojnurd, Iran

\author{
*Corresponding Author: \\ North Khorasan University of \\ Medical Sciences, Bojnurd, \\ Iran \\ Email: \\ mehdiharesabadi@gmail.com
}

\begin{abstract}
Background \& Objectives: It is generally believed that medical sciences students face tremendous stress in the course of their study, these stresses affects their quality of life. Regarding the importance of this feature, we decided to determine quality of life in North khorasan University of medical Sciences in 2011.

Material and Methods: A descriptive analytical (cross-sectional) study was conducted on students of North khorasan University of medical Sciences $(n=300)$ in 2011. The research tools included the questionnaires of demographic information and SF-36, a validated instrument for mental and physical health assessment. The data were analyzed by SPSS-16 software and presented with nonparametric tests such as Kruscal -Wallis and man-witney.

Results: The results showed that 115(38.3\%) of students were male and 185 (61.7\%) were female. 15.2\% of students experienced very weak level of quality of life, 26.4\% weak level, $32.9 \%$ good level and $25.5 \%$ very well level of quality of life. There was significant relationship between the obtained score of quality of life and level of interest in field of education, satisfy of facilities and field of education
\end{abstract}

Conclusion: The results showed that more than of students experienced good level of quality of life. The results suggest paying more attention to HRQOL and planning for promotion students' HRQOL.

Keywords: short form quality of life questionnaire(SF-36), medicine science students, quality of life 